\title{
HEART RATE VARIABILITY AS A METHOD FOR ASSESSMENT OF THE AUTONOMIC NERVOUS SYSTEM AND THE ADAPTATIONS TO DIFFERENT PHYSIOLOGICAL AND PATHOLOGICAL CONDITIONS
}

Zdravko Z. Taralov*, Kiril V. Terziyski, Stefan S. Kostianev

Department of Pathophysiology, Faculty of Medicine, Medical University, Plovdiv, Bulgaria

\section{ВАРИАБЕЛЬНОСТЬ СЕРДЕЧНОГО РИТМА В КАЧЕСТВЕ МЕТОДА ОЦЕНКИ СОСТО- ЯНИЯ ВЕГЕТАТИВНОЙ НЕРВНОЙ СИСТЕМЫ И ЕЁ АДАПТАЦИИ К РАЗЛИЧНЫМ ФИЗИОЛОГИЧЕСКИМ И ПАТОЛОГИЧЕСКИМ СОСТОЯНИЯМ}

\author{
Здравко 3. Таралов*, Кирил В. Терзийски, Стефан С. Костянев \\ Кафедра патологической физиологии, Факультет медичины, Медицинский университет, Пловдив,
} Болгария

\begin{abstract}
The autonomic nervous system controls the smooth muscles of the internal organs, the cardiovascular system and the secretory function of the glands and plays a major role in the processes of adaptation. Heart rate variability is a non-invasive and easily applicable method for the assessment of its activity. The following review describes the origin, parameters and characteristics of this method and its potential for evaluation of the changes of the autonomic nervous system activity in different physiological and pathological conditions such as exogenous hypoxia, physical exercise and sleep. The application of heart rate variability in daily clinical practice would be beneficial for the diagnostics, the outcome prognosis and the assessment of the effect of treatment in various diseases.
\end{abstract}

Key words: autonomic nervous system, heart rate variability, hypoxia, physical exercise, sleep

Folia Medica 2015;57(3\&4):173-180 Copyright (C) 2015 Medical University, Plovdiv

\section{РЕЗЮМЕ}

Вегетативная нервная система контролирует гладкую мускулатуру внутренних органов, сердечнососудистой системы и секреторную функцию желез и играет основную роль в процессе адаптации. Вариабельность сердечного ритма является доступным и неинвазивным методом оценки её активности. Настоящий обзор описывает происхождение, параметры и характеристики данного метода и его потенциал для оценки изменений в активности вегетативной нервной системы при таких различных физиологических и патологических состояниях как экзогенная гипоксия, физическая нагрузка и сон. Применение вариабельности сердечного ритма в повседневной клинической практике может повысить качество диагностики, прогноза и оценки эффективности лечения различных заболеваний.

Ключевые слова: вегетативная нервная система, вариабельность сердечного ритма, гипоксия, физическая нагрузка, сон

\section{AUTONOMIC NERVOUS SYSTEM - BASIC CHARACTERISTICS}

The autonomic nervous system (ANS) controls the smooth muscles of the internal organs, the cardiovascular system and the secretory function of the glands. It comprises sympathetic (SNS) and parasympathetic (PSNS) branches, which differ in their anatomy and function. Sympathetic effects are diffuse, generalized and fast and serve physiological defense mechanisms in response to extreme stimuli and conditions such as fear, danger, hypoxia, physical exercise, mental stress etc. They comprise tachycardia, hypertension, vasoconstriction, mydriasis, bronchodilation, etc. In contrast, parasympathetic effects are localized and are generally related to the maintainance of restorative and energy-saving

Article's history: Received: 09 Sep 2015; Received in a revised form: 05 Jan 2016; Accepted: 07 Jan 2016

*Correspondence and reprint request to: Z. Taralov, Department of Pathophysiology, Medical Faculty, Medical University-Plovdiv; E-mail: ztaralov@pathophysiology.info; Tel.:+359895193686 
functions for a longer period of time, e.g. bradycardia, hypotension, myosis, bronchospasm. ${ }^{1-3}$ Under stress (physical exercise, hypoxia, etc.) the organism activates the sympathetic nervous system and the hypothalamic-pituitary-adrenal axis, facilitating adaptation. (General Adaptation Syndrome by Hans Selye). ${ }^{4}$ However, an extremely strong and longacting stress can overwhelm the adaptive capacity and result in distress.

Considering the leading role of the ANS in adaptation, the assessment of it and of its branches activity is very important for the characterization of the adaptive processes. Heart rate variability (HRV) is a reliable, informative and applicable in daily practice method for that purpose.

\section{HEART RATE VARIABILITY - A HISTORICAL REVIEW}

HRV is the variation over time of the period between consecutive heartbeats and it is predominantly dependent on the extrinsic regulation of the heart rate. $^{5}$

Long before the development of the electrocardiograph (ECG) and the modern technologies for HRV registration, physicians realized the potential importance of heart rhythms and their connection with the ANS. The study of these rhythms occupied a leading position in the diagnostics of many diseases in Ancient China. The first documented observation of this phenomenon is attributed to Hales (1733), who monitored the cyclic changes in the blood pressure and the heart rate associated with breathing in horses. By developing the cymograph, Ludwig (1847) managed to record the acceleration of the heart rate during inspiration and its slowing during expiration in dogs, which is probably the first recorded case of respiratory arrhythmia (RA). The subsequent studies of Dondres (1868) focused on the link between breathing, heart rate and the vagus nerve. ${ }^{6}$ The invention of the modern electrocardiograph and computerized systems turned the measurement of HRV into an easily applicable method in practice and the „golden standard“ in the noninvasive assessment of the ANS. ${ }^{5}$

\section{HRV ANALYSIS, PARAMETERS AND INTERPRETATION}

The detailed HRV analysis includes three main components - time domain, frequency (parametric) domain and non-linear analysis. (Fig. 1)

The time domain analysis provides average values of the variations for different periods of time. The main parameters derived from time domain analysis are SDNN - standard deviation of normalto-normal inter-beat interval and RMSSD - root mean square of successive RR interval difference. The first parameter is a direct reflection of heart rate variability and presents the overall activity of the ANS, and the second one is associated with the activity of the PSNS. ${ }^{6-8}$

The frequency domain parameters of HRV are calculated by spectral analysis. Based on Fast Fourier Transform or Autoregressive analysis, the variations are divided in frequency bands: HF - high frequency $(0.15-0.40 \mathrm{~Hz})$; LF- low frequency $(0.04-0.1 \mathrm{~Hz})$; VLF - very low frequency $(0.017-0.04 \mathrm{~Hz})$ and ULF-ultra low frequency $(<0.017 \mathrm{~Hz})$.

HF reflects the activity of the PSNS while LF is a result of the activity of both the SNS and the PSNS, but since it is the only indicator to assess the activity of the SNS, it is accepted as a parameter describing it. There is still no unanimous opinion on the origins and the interpretation of very- and ultra-low frequencies. It is assumed that VLF is associated with the activity of the renin-angiotensin-aldosterone system, and ULF is dictated by the circadian rhythms but their origin is still unclear and disputable. Total power is a parameter, which corresponds to SDNN. The LF/ HF index is thought to reflect the interaction of the two branches of the ANS $^{5,7}$ (Table 1).

HRV could also be assessed by non-linear mathematical analysis such as Poincaré plot analysis. It is a geometrical model, presenting each interval as a function of the previous. The three main parameters obtained are: standard deviation one (SD1) - associated with rapid variations between heart beats and standard deviation two (SD2) - responsible for the long-term variations and the relationship between them (SD1 / SD2 index).

Another non-linear parameter is the Sample Entropy (SampEn) - a simple index, reflecting the overall complexity and predictability of the time series of HRV.

Autonomic cardiovascular control is not a simple SNS or PSNS predominance but includes a complex interaction via different circulatory reflexes, such as baro- and chemoreceptor and sympatho-sympathetic reflexes, various molecular and hormonal factors, and central oscillations may also affect the variability and are responsible for the overall complexity of the signal. Under different physiological or pathological conditions any of these mechanisms can become dominant inhibiting some of the others and thereby it may reduce the complexity of the HRV and lead to "simplification" 

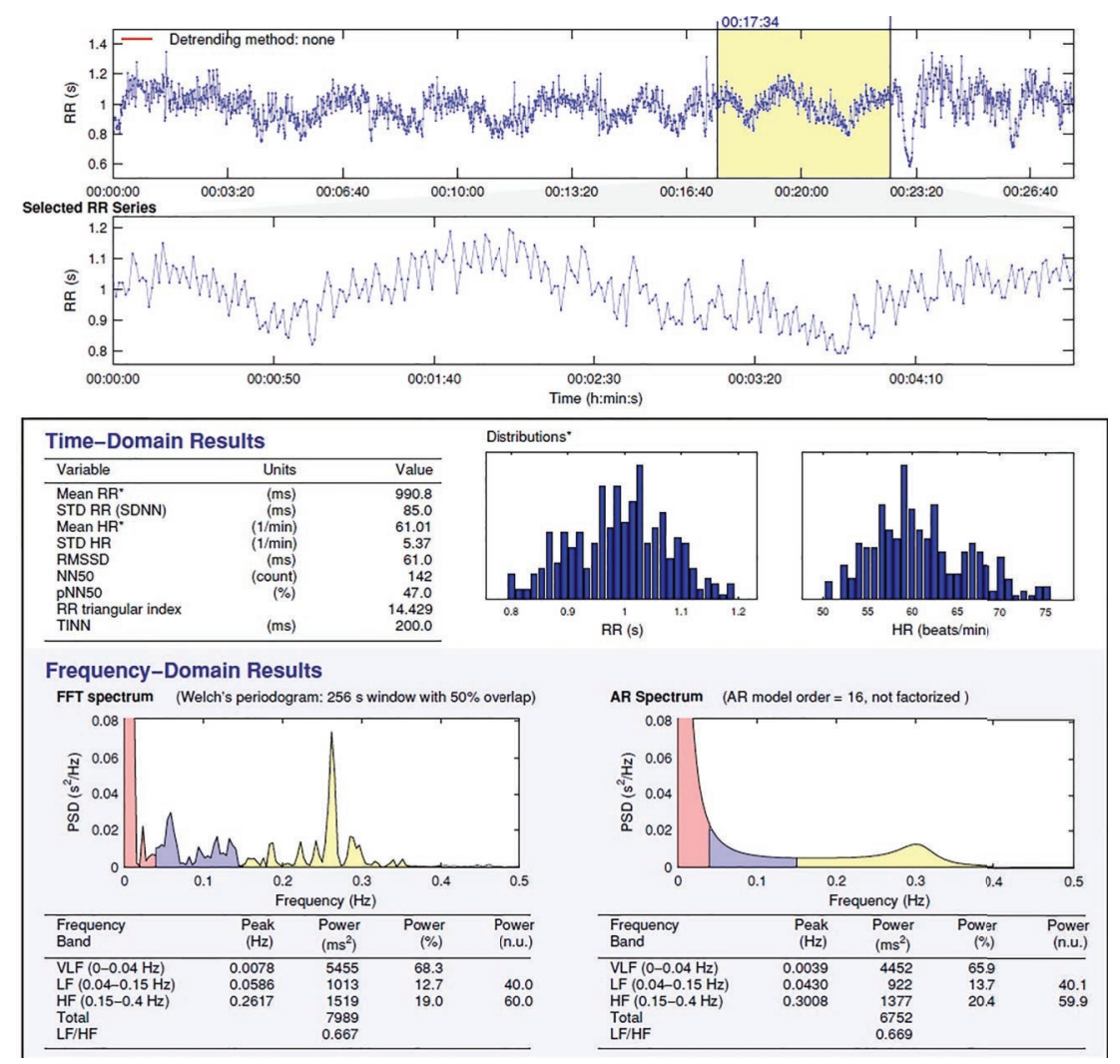

Legend: Time domain parameters: MeanRR (mean beat-to-beat interval), SDNN (standard deviation of normal-to-normal R-R intervals), MeanHR (mean heart rate), STDHR (standard deviation of heart frequency), RMSSD (the square root of the mean squared difference between adjacent N-N intervals), NN50 (number of differences between adjacent RR intervals), pNN50 (percentage of differences between adjacent RR intervals), TINN (triangular interpolation of RR intervals); Frequency domain parameters: VLF (very low frequency), LF (low frequency), HF (high frequency).

Figure 1. A report from HRV analysis with Kubios HRV software.

Table 1. Main parameters from HRV analysis

\begin{tabular}{lll}
\hline \multicolumn{1}{c}{ Parameter } & Unit & \multicolumn{1}{c}{ Interpretation } \\
\hline Time domain & $\mathrm{ms}$ & Overall variability \\
\hline SDNN & $\mathrm{ms}$ & PSNS activity \\
RMSSD & & \\
\hline Frequency domain & $\mathrm{ms}^{2}, \mathrm{nu}$ & PSNS activity \\
\hline HF & $\mathrm{ms}^{2}, \mathrm{nu}$ & SNS and PSNS activity \\
LF & $\mathrm{ms}^{2}$ & RAAS, termoregulation, metabolic factor \\
VLF & $\mathrm{ms}^{2}$ & Overall variability \\
Total power & & SNS/PSNS interaction \\
LF/HF & & \\
\hline Non-linear dynamics & & High frequency fluctuations \\
Poincaré plot (SD1) & $\mathrm{ms}$ & Low-frequency fluctuations \\
Poincaré plot (SD2) & $\mathrm{ms}$ & Complexity and predictability of the signal \\
Sample Entropy & &
\end{tabular}

Legend: SDNN (standard deviation of normal to normal R-R intervals), RMSSD (the square root of the mean squared difference between adjacent N-N intervals), HF(high frequency), LF(low frequency), VLF (very low frequency), SD (standard deviation), RAAS (renin-angiotensin-aldosterone system). 
of the cardiovascular control. ${ }^{9}$

The advantage of the non-linear analysis is its lesser sensitivity to the length of the heart rate record and the presence of artifacts or short arrhythmias, while the drawback is the lack of consensus on the interpretation and meaning of these parameters. ${ }^{8,10}$

Duration of the record for HRV analysis is very important and is determined by the nature of the research. The frequency domain parameters (HF, LF) are more sensitive to sympathovagal modulation and shorter recording length is preferred (e.g. 5 minutes). Although time-domain parameters can be derived from a short-term investigation, they are more accurately calculated from longer recordings. ${ }^{7}$

\section{ORIGIN OF HRV}

The response of the heart to SNS and PSNS signals differs in terms of speed. Its onset is after about 0.5 $\mathrm{sec}$, returning to baseline in approximately $1 \mathrm{sec}$ in vagal stimulation, while sympathetic stimulation exerts its effect more slowly in about 1-2 sec, ebbs off fast in up to $4 \mathrm{sec}$ and returns to baseline after about $20 \mathrm{sec}$. These values mirror perfectly the frequency domain bands of the HRV - HF and LF. ${ }^{6}$

The delay in the excitation of the heart is attributed to the time necessary for the membrane transmission of the impulse. The coupling between the activation of the muscarine receptors and the changes in the membrane ion-channels is accomplished by signal molecules situated close to the cellular membrane and thus the response to parasympathetic activation is fast. In contrast, the adrenergic stimulation requires secondary messenger activation by a cytoplasm proteinkinase delaying the response to sympathetic activation. ${ }^{6}$ Respiratory arrhythmia (RA) plays an important role in HF genesis as well. Therefore, HRV parameters are strongly influenced by the rate and depth of breathing, the end-tidal partial pressure of carbon dioxide $\left(\mathrm{PETCO}_{2}\right)$ and the interplay of inhalation/ exhalation in terms of time and dead space. ${ }^{11-13}$

\section{HRV IN DIFFERENT PHYSIOLOGICAL AND PATHOLOGICAL CONDITIONS}

Age and gender. In general, women and younger people have higher variability. HRV decreases with age to a similar extent in both males and females. Children not only have higher values in the frequency domain parameters, but also have stronger response to different stressful stimuli.

Fatigue. Immediately after heavy exercise the SNS activity remains high in order to meet the metabolic demands, imposed to the organism, while later (including during sleep after exercise), the PSNS prevails to ensure better recovery. ${ }^{5,8}$

Emotions may change the activity of the ANS in one or the other direction. ${ }^{14}$

Drugs. All drugs, influencing the activity of the ANS, affect the HRV parameters. Therefore, HRV could be used in the assessment of the effectiveness of beta-blockers treatment.

Smoking. Smoking leads to sympathetic predominance and a decrease in the overall variability. Furthermore, smokers react less to maneuvers triggering vagal stimulation (Valsalva). It is believed that exactly these pathophysiological mechanisms are responsible for the detrimental effects of smoking on the heart.

Alcohol. A correlation between the daily alcohol consumption and the vagal activity decrease has been established in people with chronic alcohol abuse.

Myocardial infarction. HRV assessment after myocardial infarction is one of the first and most widely used applications of the method. It could provide important information about sympathetic predominance and impaired vagal control on the heart after myocardial infarction, which are strong predictors of survival and the risk of rhythm and conductive disorders associated with sudden cardiac death.

Arterial hypertension (AH). HRV is strongly decreased in patients with $\mathrm{AH}$-induced left ventricle hypertrophy, which can be explained by the impaired baroreflex sensitivity in this pathological condition.

Nervous system disorders. Various neurological disorders and depression could lead to autonomic dysfunction, which makes HRV an applicable method in neurological and psychiatric practice.

Diabetes leads to autonomic dysfunction and a decrease in the total variability of the heart rate, which is predictive for cardiovascular complications such as sudden cardiac death.

Renal failure. Electrolyte disorders in renal failure are associated with a decrease in all frequency domain HRV parameters. It has been proven that hemodialysis leads to a significant increase in HF in patients with chronic renal failure..$^{5,8}$

\section{HRV DURING EXPOSURE TO EXOGENOUS HYPOXIA AND THE ROLE OF THE ANS IN THE ADAPTATIONS TO HYPOXIA}

Prolonged or periodical exposure to exogenous hypoxia leads to a number of adaptations in the systems that intake, transport and utilize oxygen ${ }^{4,15}$. Most of the fast adaptations, such as increase in heart rate, which can be observed immediately after 
the application of the hypoxic stimulus, are associated with the activity of the ANS. ${ }^{16,17}$ A number of studies use HRV to assess the early adaptation to high altitude hypoxic exposure. ${ }^{18-21}$ What is more, HRV has been used as a predictor of acute mountain sickness. ${ }^{22}$

Acute exposure to exogenous hypoxia leads to a decrease in the overall variability - Total power and SDNN, as well as LF/HF index increase demonstrating the sympathetic predominance. ${ }^{23-26}$ It is caused by the activation of the peripheral chemoreceptors with consequent vasoconstriction and tachycardia, which are better emphasized in higher hypoxic ventilator response (HVR). However, this initial response of the body is partially counteracted by secondary baroreceptor activation caused by the vasoconstriction ${ }^{27,28}$. Thus, the baroreflex stimulation suppresses the SNS activation, caused by acute hypoxia (+). Long-term stay at high altitude and intermittent hypoxic training (IHT) lead to augmented chemoreceptor sensitivity (higher HVR $)^{30,31}$ ), and a shift from sympathetic to parasympathetic predominance, expressed by increased HRV. ${ }^{32-34}$ Thus, many of the adaptations to hypoxia related to the ANS are a result of increased baroreceptor activity, which is supported by the rise in HRV at high altitude sojourn. Our observation of gradually rising parasympathetic activity after a 10-day protocol with one-hour daily normobaric hypoxic exposure supports this statement (Fig. 2).

\section{ROLE OF THE ANS DURING AND AFTER PHYSICAL EXERCISE AND APPLICATION OF HRV IN SPORT}

ANS plays a key role in the adaptations to physical exercise. ${ }^{35}$ It is widely accepted, that elite sportsmen, especially endurance athletes, who face high aerobic demands, have PSNS predominance at rest ${ }^{36}$, resulting in bradycardia. Somlev et al. show that HRV parameters (particularly increased SDNN, RMSSD and HF and decreased or unchanged LF and decreased LF/ HF index) correlate with the fitness level in elite athletes. ${ }^{37,38}$

There is no consensus in the literature whether HRV could be used as an indicator of the aerobic capacity of athletes, since it only reflects the dynamics of the ANS, but not the oxygen-utilisation processes in the body. The possible link between maximal oxygen consumption $\left(\mathrm{VO}_{2} \max \right)$ and $\mathrm{HRV}$ is also contradictory. ${ }^{39-41}$

On the other hand fatigue can affect the activity of the ANS. During physical exercise an activation of the SNS and deactivation of the PSNS are ob-

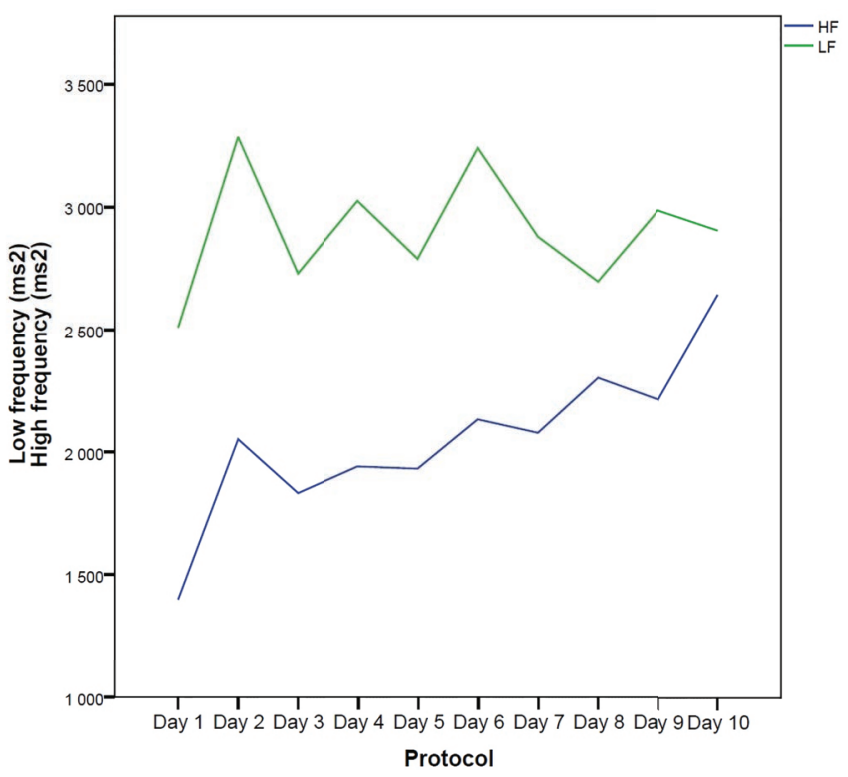

Figure 2. An increase in the PSNS activity (HF), after 10-day protocol with 1-hour intermittent normobaric hypoxic stimulation $\left(\mathrm{FiO}_{2}=12.3 \pm 1.5 \%\right)$.

served, while the opposite changes (first, increase in the activity of the PSNS and later sympathetic withdrawal) occur in the recovery period. ${ }^{42}$ Measuring the state of PSNS reactivation via HRV may be used in the assessment of the effect of particular physical exercise on the ANS.

Heart rate recovery (HRR) is one of the most frequently used parameters in sport practice for the assessment of the recovery after physical exercise and the presence of fatigue. HRV is a method that could be used for the same purpose ${ }^{35}$, since both HRV and HRR are phenomena which are strongly associated with the PSNS reactivation after physical exercise. ${ }^{43}$ It has been proven that the intensity of the physical exercise correlates negatively with HRR, as well as with HF and Total power. ${ }^{44,45}$ Therefore, HRV analysis could be superior to the widely used simple measurement of the heart rate in the morning regarding the assessment of the recovery during the training process. ${ }^{46}$

\section{HRV DURING NORMAL SLEEP AND IN DIFFERENT SLEEP DISORDERS}

Although sleep has been viewed as a static condition of recovery in the past, nowadays, it is known to be a heterogenous state and many biological processes, including cardio-vascular ones, significantly change their activity (both increase and decrease) under the control of the ANS. Therefore, the autonomic regulation in physiological and pathological sleep may be assessed by HRV analysis. ${ }^{9}$ 
The activity of the SNS and the PSNS shows circadian and ultradian variations between the states of wakefulness, NREM (Non rapid eyes movement) and REM (Rapid eyes movement) sleep. While N1 to N3 sleep stages (NREM) are those of increasing synchronization with a decrease in heart rate and blood pressure (gradually increasing PSNS activity), the activation of the cardiovascular system during REM sleep may be even higher than during wakefulness (SNS predominance, mainly due to PSNS withdrawal). Thus, falling asleep is associated with an increase in the overall variability and HF and a decrease in LF and the transition to REM is related to a decrease in HRV, increase in LF and LF/HF and a parasympathetic withdrawal with decreased HF. These fluctuations in the activity of the ANS may explain the higher rate of cardio-vascular incidence in the early morning hours, when REM sleep is mostly concentrated $(+)$.

Different sleep disorders are associated with a different model of HRV changes. Obstructive sleep apnea (OSA) is a pathological condition, characterized by repeated apneas and/or hypopneas during sleep with preserved or increasing breathing effort due to a total or partial closure of the upper airways during inspiration. This leads to impairment of the chemo- and baroreflex regulation with a consequent SNS hyperactivation and PSNS withdrawal, which is additionally increased by arousals. ${ }^{49}$ SNS activation in OSA patients is present during the day as well, which is associated with higher cardiovascular risk..$^{50}$ Patients with OSA have decreased HRV and HF and increased LF and LF/HF. ${ }^{9}$ What is more, the severity of OSA strongly correlates with the LF/HF increase, which makes this index very suitable for monitoring of OSA patients. ${ }^{51}$

The opposite changes have been described with CPAP (Continuous positive airway pressure) treatment - a significant increase in the overall variability, a decrease in the sympathetic hyperactivity and an improvement in the baroreflex control (HF rise and LF/HF fall). These changes in the activity of the ANS and the HRV parameters are observed even after a single session of CPAP treatment. ${ }^{52,53}$

Cheynne-Stokes periodic breathing during sleep is a phenomenon, which is often observed in patients with chronic heart failure (CHF). ${ }^{54}$ Szollosi et al found that it generates a very low frequency band (VLF) fluctuations in the HRV in a 10-minute recording that includes apnea periods. Therefore, HRV is capable of differentiating patients with OSA from patients with central sleep apnea (CSA), since each of these sleep disorders leads to a different model of VLF changes lower in OSA and higher in $\mathrm{CSA}^{55}$ ) (Fig. 3).

Since HRV is strongly dependent on respiration, the analysis of the results according to the ANS activity should be made with caution in patients with sleep breathing disorders to avoid misinterpretation.

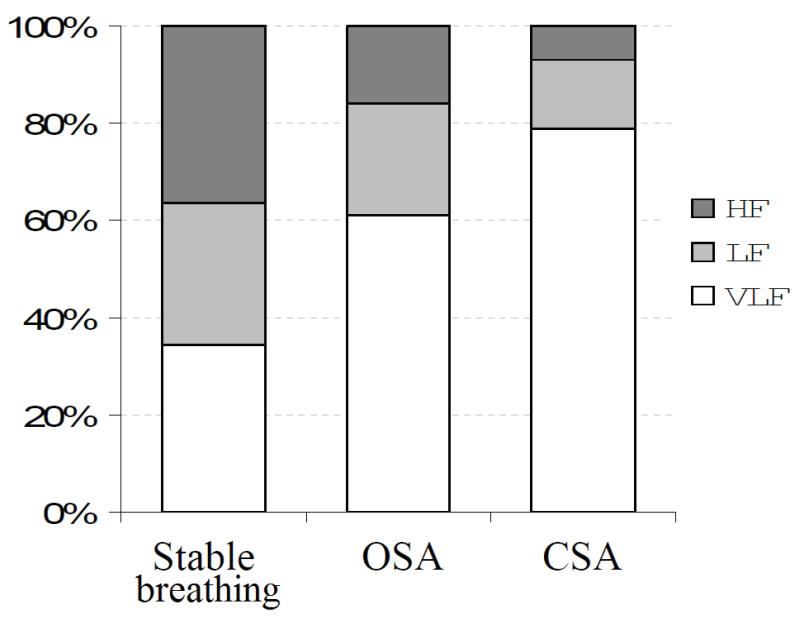

Figure 3. Difference in frequency distribution of HRV analysis in normal sleep, obstructive sleep apnea (OSA) and central sleep apnea (CSA). Adapted to Szollosi I. ${ }^{53}$

\section{CONCLUSIONS}

HRV is a highly sensitive and informative method for the assessment of different physiological and pathological conditions, related to changes in the activity of the ANS. Its application in the daily clinical practice would be beneficial for the diagnostics, the outcome prognosis and the assessment of the effect of treatment in various diseases. It could also be applied in the sports and alpine practice to improve the individual performance of the athletes.

\section{REFERENCES}

1. Shotekov P. Neurology. In: Shotekov P. Autonomic nervous system. 2nd ed, Sofia: MI ARSO; 2004. p. 106-17 (Bulgarian).

2. O'Donnell A, Glasgow B. The autonomic nervous system. The New Zealand Medical Student Journal Number 2011;13:11-3.

3. Nedel L. Encyclopedia of cognitive science. $\ln$ : Berntson GG, Sarter M, Cacioppo JT. Autonomic nervous system. Volume 2. Nature Publishing Group, London, New York, Tokyo;2006:301-8.

4. Illuchev D, Stoinev A. Introduction to pathophysiology. In: Illuchev D, Marinov B, Murdzheva M. Body reactivity and resistance. Plovdiv: Raykov Medical 
Publishing House; 2010. p. 69-116 (Bulgarian).

5. Rajdendra AU, Suri J, Spaan J, Kirshnan S. Advances in Cardiac Signal Processing. ln: Rajendra AU, Joseph P, Kannathal N, Min LM, Suri J. Heart rate variability. Springer 2007:121-56.

6. Berntson GG, Bigger T, Eckberg DL, et al. Heart rate variability: origins, methods and interpretive caveats. Psychophysiology 1997:34:623-48.

7. Task force of The European Society of Cardiology and The North American Society of Pacing and Electrophysiology. Heart rate variability. Standards of measurement, physiological interpretation and clinical use. European Heart Journal 1996:17:354-81.

8. Rajendra A, Joseph K, Kannathal N, et al. Heart rate variability: a review. Med Bio Eng Comput 2006:44:1031-51.

9. Tobaldini E, Nobili L, Strada S et al. Heart rate variability in normal and pathological sleep. Front Physiol 2013:4:294.

10. Voss A, Schulz S, Schroeder R, et al. Methods derived from nonlinear dynamics for analyzing heart rate variability. Phil Trans R Soc 2008:367:277-96.

11. Berntson G, Cacioppo J, Quigley K. Respiratory sinus arrhythmia: autonomic origins, physiological mechanisms and psychophysiological implications. Psychophysiology 1993:30:183-96.

12. Hirsch J, Bishop B. Respiratory sinus arrhythmia in humans: how breathing pattern modulates heart rate. Am J Physiol 1981:241:(Heart Circ. Physiol.10):H620-H629.

13. Tripathi CKK. Respiration and heart rate variability: a review with special reference to its application in aerospace medicine. IJASM 2004:48(1):64-75.

14. Kreibig S. Autonomic nervous system activity in emotion: A review. Biological Psychology 2010:84:394-421.

15.Bartsch P, Dehnert C, Friedmann-Bette B, et al. Intermittent hypoxia at rest for improvement of athletic performance. Scand J Med Sci Sports 2008:18(Suppl. 1):50-6.

16. Paralikar SJ, Paralikar JH. High-altitude medicine. Indian J Occup Environ Med. 2010:14(1): 6-12.

17.Peacock AJ. Oxygen at high altitude. BMJ 1998: 317:10636.

18. Hainsworth R, Drinkhill MJ, Rivera-Chira M. The autonomic nervous system at high altitude. Clin Auton Res 2007:17:13-9.

19. Kanai M, Nishihara F, Shiga T, et al. Alterations in autonomic nervous control of heart rate among tourists at 2700 and $3700 \mathrm{~m}$ above sea level. Wilderness and Environmental Medicine 2001:12:8-12.

20.Liu Y, Cao Z, Yang J et al. Heart rate variability analysis during stepwise hypoxia from $3000 \mathrm{~m}$ to 4500 m. Life Sci J 2013:10(3):1127-31.

21. Farinelli CCJ, Kayser B, Binzoni T, Cerretelli P, Gi- rardier L. Autonomic nervous control of heart rate at altitude (5050 m). Eur J Appl Physiol 1994:69:502-7.

22. Karinen HM, Uusitalo A, Vaha-Ypya H, et al. Heart rate variability changes at $2400 \mathrm{~m}$ altitude predicts acute mountain sickness on further ascent at 3000$4300 \mathrm{~m}$ altitude. Frontiers in physiology 2012:3:Article 336.

23. Bhaumik G, Dass D, Bhattacharyya D et al. Heart rate variability changes during first week of acclimatization to $3500 \mathrm{~m}$ altitude in indian military personnel. Indian J Physiol Pharmacol 2013:57(1):16-22.

24. Sevre K, Bendz B, Hanko E, et al. Reduced autonomic activity during stepwise exposure to high altitude. Acta Physiol Scand 2001:173:404-17.

25.Perini R, Milesi S, Biancardi 1, Veicsteinas A. Effects of high altitude acclimatization on heart rate variability in resting humans. Eur J Appl Physiol 1996:73:521-8.

26. Chen YC, Lin FC, Shiao GM, et al. Effect of rapid ascent to high altitude on autonomic cardiovascular modulation. The American Journal of the Medical Sciences 2008:336:248-53.

27. Bernardi L, Passino C, Spadacini G, et al. Cardiovascular autonomic modulation and activity of carotid baroreceptors at altitude. Clinical Science 1998:95:565-73.

28. Marshall JM. Chemoreceptors and cardiovascular control in acute and chronic system hypoxia. Braz J Med Biol Res 1998:31(7):863-88.

29. S. Rey, MP Tarvainen, PA Karjalainen, et al. Dynamic time-varying analysis of heart rate and blood pressure variability in cats exposed to short-term chronic intermittent hypoxia. Am J Physiol Regul Integr Comp Physiol 2008:295:R28-R37.

30. Thomas E, Kupper AH, Schoffl V. Preacclimatization in hypoxic chamber for high altitude sojourns. Sleep Breath 2010:14:187-91.

31. Garcia N, Hopkins SR, Powell FL. Intermittent vs continuous hypoxia: effects on ventilation and erythropoiesis in humans. Wilderness and environmental medicine 2000:11:172-9.

32. Bernardi L, Passino C, Serebrovskaya Z, et al. Respiratory and cardiovascular adaptations to progressive hypoxia. European Heart Journal 2001:22:879-86.

33. Burtscher M, Brandstatter E, Gatterer H. Preacclimatization in simulated altitudes. Sleep Breath 2008:12(2):109-14.

34. Cornolo J, Mollard P, Brugniaux JV, et al. Autonomic control of the cardiovascular system during acclimatization to high altitude: effects of sildenafil. J Appl Physiol 2004:97:935-40.

35. Javorka M, Zila I, Balharek T, et al. Heart rate recovery after exercise: relations to heart rate variability and complexity. Brazilian Journal of Medical and Biological Research 2002:35:991-1000. 
36. Martinmaki K, Rusko H, Kooistra L et al. Intraindividual validation of heart rate variability indexes to measure vagal effects on hearts. Am J Physiol Heart Circ Physiol 2006:290:H640-H647.

37. Somlev P. Effect of high training on heart rate variability. Sport y nauka 2011:5;32-7 (Bulgarian).

38. Somlev P, Uzunova G, Pavlova E. Heart rate variability at rest in elite and former soccer players. Scripta Scientifica Medica 2012:44:89-91.

39. Tulppo M, Makikallio T, Seppanen T et al. Vagal modulation of heart rate during exercise: effects of age and physical fitness. Am J Physiol Heart Circ Physiol 1997:274:H424-H429.

40.Lazoglu AH, Glace B, Gleim G, et al. Exercise and heart rate variability. Am Heart J 1996:131:825-7.

41. Marocolo M, Nadal J, Bechimol Barbosa PR. The effect of an aerobic training program on the electricial remodeling of the heart: high-frequency components of the signal-averaged electrocardiogram are predictors of the maximal aerobic power. Braz J Med Biol Res 2007:40(2):199-208.

42. Auber AE, Seps B, Beckers F. Heart rate variability in athletes. Sport Med 2003:33(12):889-919.

43. Buchheit M, Papelier Y, Laursen PB, et al. Noninvasive assessment of cardiac parasympathetic function: postexercise heart rate recovery and heart rate variability? Am J Physiol Heart Circ Physiol 2007:293:H8-H10.

44. Kaikkonen P, Nummela A, Rusko H. Heart rate variability dynamics during early recovery after different endurance exercises. Eur J Appl Physiol 2007:102:79-86.

45. Martinmaki K, Rusko H. Time-frequency analysis of heart rate variability during immediate recovery from low and high intensity exercise. Eur J Appl
Physiol 2008:102:353-60.

46. Buchheit M, Mendez-Villanueva, Quod MJ, et al. Determinants of the variability of the heart rate measures during a competitive period in young soccer players. Eur J Appl Physiol 2010:109:869-78.

47. Vanoli E, Adamson PB, Lin B, et al. Heart rate variability during specific sleep stages. Circulation 1995: 91(7):1918-22.

48. Elsenbruch S, Harnish MJ, Orr WC. Heart rate variability during waking and sleep in healthy males and females. Sleep 1999:22(8):1067-71.

49. Bonnet MH, Arand DL. Heart rate variability: sleep stage, time of night, and arousal influences. Electroencephalogr Clin Neurophysiol 1997:102(5):390-6

50. Jo JA, Blasi A, Balladares E, et al. Determinants of heart rate variability in obstructive sleep apnea syndrome during wakefulness and sleep. Am J Physiol Heart Circ Physiol 2005:288:H1103-H1112.

51. Park DH, Shin CJ, Hong SC, et al. Correlation between the severity of obstructive sleep apnea and heart rate variability indices. J Korean Med Sci 2008:23:226-31.

52.Kufoy E, Palma JA, Lopez J, et al. Changes in the heart rate variability in patients with obstructive sleep apnea and its response to acute CPAP treatment. Plos one 2012:7(3):e33769.

53. Bradley TD, Floras JG. Sleep apnea and heart failure. Part I: Obstructive sleep apnea. Circulation 2003:107:1671-8.

54. Bradley TD, Floras JS, et al. Sleep apnea and heart failure. Part II: Central sleep apnea. Circulation 2003:107:1822-6.

55.Szollosi I, Krum H, Kaye D, et al. Sleep apnea in heart failure increases heart rate variability and sympathetic dominance. Sleep 2007:30(11):1509-14. 